\title{
Bio-sludge from the Pulp and Paper Industry as Feed for Black Soldier Fly Larvae: A Study of Critical Factors for Growth and Survival
}

\author{
R. Norgren ${ }^{1,2}$ (D) O. Björkqvist ${ }^{3} \cdot$ A. Jonsson ${ }^{4}$
}

Received: 5 November 2018 / Accepted: 21 October 2019 / Published online: 31 October 2019

(c) The Author(s) 2019

\begin{abstract}
Pulp and paper bio-sludge (PPBS) has low economic value and is therefore often composted or incinerated. The purpose of this work is to evaluate the feasibility of using PPBS to breed black soldier fly (Hermetia illucens) larvae (BSFL), so improving resource efficiency and supplying protein and fat to the animal feed market. BSFL were reared on PPBS in a climate chamber on a laboratory scale in order to assess nutrient deficiency, inhibition and whether the BSFL recycle the PPBS well or not. The PPBS used came from a chemi-thermomechanical pulp/groundwood pulp mill. The effect of supplementing nutrient solution added either into the PPBS or as a free liquid surface were studied. Prepupae dry weight, survival rate until prepupae stage and residual dry PPBS were measured. The addition of reference diet leachate into the PPBS did not have a significant impact on the weight of the prepupae $(2.0 \mathrm{mg})$ but the survival rate was significantly higher $(16.0 \%)$. On the other hand, the addition of reference diet leachate as a free liquid surface had a significant impact on both the weight of the prepupae $(4.8 \mathrm{mg}$ ) and the survival rate (25.7\%). The bio-conversion and PPBS-reduction was as best 0.4 and $3.2 \%$ respectively. This study has proven that the nutrients in PPBS are not readily available to the larvae. Addition of reference diet leachate increase the survival rate which opens up for possibilities of co-digestion. However, it is clear that under the tested conditions, BSFL is not recycling PPBS well and BSFL as a method for recycling of PPBS need further research.
\end{abstract}

\section{Graphic Abstract}

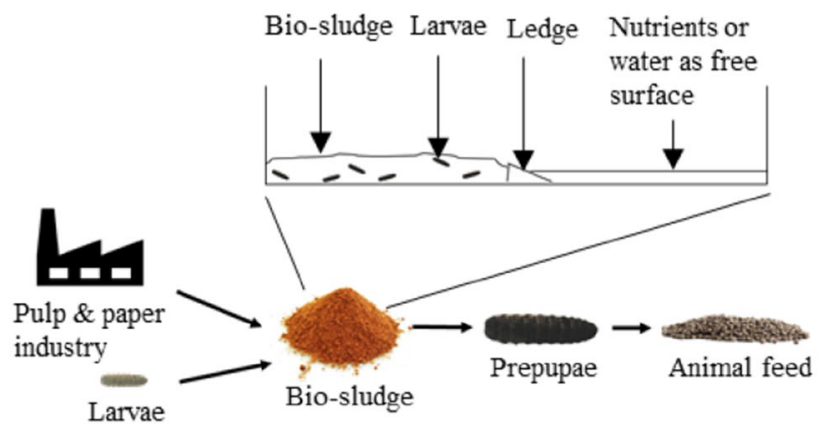

Keywords Pulp and paper bio-sludges · Valorization · Black soldier fly larvae

\section{Statement of Novelty}

Valorization of pulp \& paper bio sludge by Black Soldier fly larvae is a novel approach. Our results show that further research on nutrient availability and co-digestion are needed.

R. Norgren

robert.norgren@ragnsells.com

Extended author information available on the last page of the article

\section{Introduction}

Treating wastewater from the pulp and paper industry produces large quantities of bio-sludge (PPBS). In Sweden alone, the yearly production amounts to $200,000-300,000$ tons [1]. The composition of PPBS varies depending on the paper mill process and wastewater treatment, but typically it contains crude protein $1.5-8.3 \%$, fat $0.3-3.3 \%$, $10-30 \%$ dry substance (DS), lignin $17-40 \%$ DS, nitrogen 
$18,000-84,000 \mathrm{mg} / \mathrm{kg}$ DS, phosphorus $1,700-21,000 \mathrm{mg} /$ $\mathrm{kg}$ DS, potassium 200-4,600 mg/kg DS and ash (27\% DS) $[2,3]$. It is also frequently contaminated with toxic heavy metals such as lead, mercury and cadmium [2]. Since the concentration of valuable substances is rather low, it has low economic value and is often incinerated or composted $[1,4]$. From a resource conservation and circular economy perspective, there is a need to search for new and improved waste recycling technologies.

A search for recycling technologies for PPBS led to three viable recycling applications: (1) bioconversion of PPBS into protein-rich feedstock for animal fodder by single cell organisms [3] (2) bioconversion into feedstock by the black soldier fly larvae (BSFL) (Hermetia illucens Linnaeus; Diptera: Stratiomyidae) [2], and (3) thermoalkaline hydrolysis of PPBS to produce second-grade cardboard and biogas [3] (Norgren et al. unpublished data). Assessment of the potential economic value of the PPBS content showed that protein generally has higher potential economic value than lignin, fat, phosphorus, nitrogen, potassium and the use of PPBS as bio fuel [2] (Norgren et al. unpublished data).

This paper investigates the potential of the BSFL as a viable recycling option to convert low-value material in PPBS to valuable protein for animal feed. The rearing of BSFL to reduce organic waste has been studied since Booram et al. [5] studied management of beef waste using BSFL. Until now, the focus has often been on converting manure or food waste into protein- and fat-rich BSFL for further processing into food and feed. Cai et al. [6] tested municipal sewage sludge as feed for BSFL and showed that BSFL can grow and survive on municipal sewage sludge. However, to the best of our knowledge no similar work has been done on PPBS. Thus, the feasibility of recycling PPBS by rearing BSFL to produce protein should be studied.

Critical factors for the prepupae weight and survival are pathogens: viruses, bacteria and fungi; toxins: heavy metals and insecticides; nutrients: protein, carbohydrates, fat, vitamins, and trace elements; multiple feed sources; selfselection; ambient factors: air temperature and humidity; and feed properties: $\mathrm{pH}$ and water content [7, 8]. In this paper, we address nutrients, pathogens and toxins since these are considered decisive for the design of a robust and economically viable industrial process. The impact of addition of reference diet leachate on prepupae dry weight, survival rate until prepupae stage and dry PPBS reduction were tested. PPBS from a chemical-thermo-mechanical pulp/ground wood pulp mill was used.

The purpose of this study is to evaluate the feasibility of PPBS as feed for BSFL by testing if PPBS can be digested or co-digested by the addition of extra nutrients to the sludge. BSFL were reared on PPBS on a laboratory scale.
Table 1 The design of study

\begin{tabular}{llc}
\hline Trial & Treatment & Box nr. \\
\hline Control 1 & Reference diet (ds 28.3\%) & $1-3$ \\
Control 2 & PPBS (ds 20.0\%) & $4-6$ \\
A & PPBS (ds 20.0\%) + water as free liquid surface & $7-9$ \\
B & PPBS mixed with leachate (ds 20.0\%) + water as & $10-12$ \\
& $\quad$ free liquid surface & \\
C & PPBS mixed with leachate (ds 20.0\%) & $13-15$ \\
D & PPBS (ds 20.0\%) + leachate as free liquid & $16-18$ \\
& surface & \\
\hline
\end{tabular}
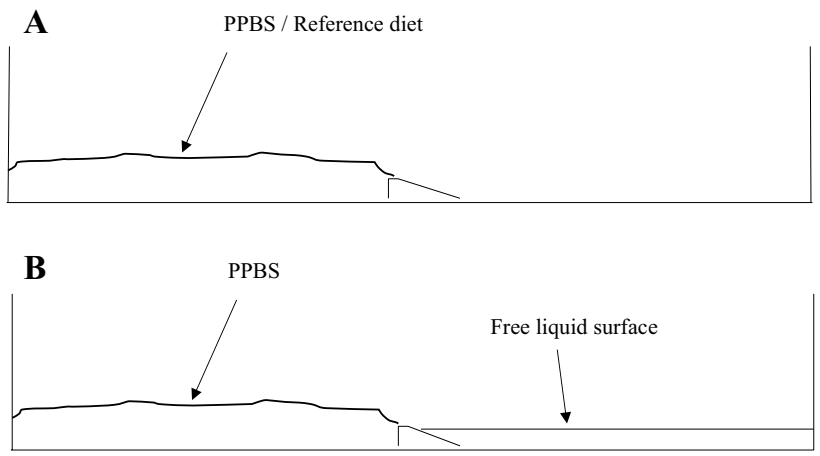

Fig. 1 Box design

Extra nutrients were added either directly to the sludge or as free liquid surface adjacent to the sludge.

\section{Methods and Materials}

\section{Experimental Design}

The experiment was designed to test the effect of supplementing nutrients and inhibiting PPBS properties by addition of reference diet leachate either mixed into the PPBS or as a free liquid surface (Table 1). Addition of water was used as a control. The experiment was carried out in (polypropylene) boxes with dimensions $(21 \times 17 \times 15 \mathrm{~cm})$. The boxes were equipped with a ledge to separate the PPBS from the free liquid surface (Fig. 1). $160 \mathrm{~g}$ of substrate (PPBS and reference diet respectively) was used in each trial and 100 larvae was added to each box at the start of the experiment. Evaporation was compensated for every day by addition of water. The amount of water given to the PPBS was based on the average evaporation from the PPBS only trial (control 2). Water was added to the free liquid surface to keep the weight of the box constant. 
Table 2 Dry substance, pH, energy and nutrients of substrates used. Numbers within parenthesis represent standard deviation

\begin{tabular}{lll}
\hline Parameter & PPBS & Reference diet \\
\hline Dry substance $(\%)$ & $20.9( \pm 0.2)$ & $27.7( \pm 0.1)$ \\
$\mathrm{pH}$ & $5.2( \pm 0.1)$ & $4.8( \pm 0.0)$ \\
Energy value (calc.) $(\mathrm{MJ} / \mathrm{kg})$ & $3.2( \pm 0.0)$ & $4.5( \pm 0.0)$ \\
Crude protein Nx6.25 $(\mathrm{g} / 100 \mathrm{~g})$ & $1.5( \pm 0.1)$ & $4.0( \pm 0.1)$ \\
Fat $(\mathrm{g} / 100 \mathrm{~g})$ & $1.7( \pm 0.1)$ & $0.9( \pm 0.1)$ \\
Carbohydrate (calc.) $(\mathrm{g} / 100 \mathrm{~g})$ & $13.6( \pm 0.2)$ & $20.0( \pm 0.0)$ \\
\hline
\end{tabular}

\section{Materials}

PPBS from a chemical-thermo-mechanical pulp/ground wood pulp mill was used in the experiments, as well as the reference diet. The reference diet was a mix of alfalfa seeds, wheat bran and maize. Table 2 shows the characteristics of the substrate used.

\section{Preparation of PPBS}

PPBS was acquired in lidded buckets from the mill. It was stored in a refrigerator until used. Before the start of the experiments $15 \mathrm{~kg}$ of PPBS were homogenized by hand. Mixtures of PPBS and liquid (tap water or reference diet leachate) was prepared and mixed (10 min) and the dry substance was measured. The mixtures were then put in the experiment boxes.

\section{Preparation of Larvae}

Swedish University of Agricultural Sciences delivered about 10,000 larvae, four days old in an envelope. The larvae were placed in a $21 \times 17 \mathrm{~cm}$ box layered at the bottom with $1 \mathrm{~cm}$ of wheat bran. The wheat bran was moistened with tap water to avoid dehydration and the box was stored in room temperature 1 day while the experiment was being prepared.

On the first day of the experiment, the 5-day old larvae were put in a $4.5 \mathrm{~mm}$ sieve. The larvae crawled through the sieve and fell onto a tray beneath where they were further separated from the wheat bran. Three times 100 larvae were counted and weighed to determine their average weight. The weight of 100 larvae was then calculated and the corresponding weight of larvae was put in each box.

\section{Preparation of Reference Diet and Leachate}

The reference diet was made from the recipe below (Fengchun 2017, personal communication):
1. $183 \mathrm{~g}$ of alfalfa pellets was added to $748 \mathrm{~g}$ of water.

2. The mix was stirred regularly by hand for $60 \mathrm{~min}$ to dissolve the pellets.

3. $67 \mathrm{~g}$ of milled maize and $75 \mathrm{~g}$ of wheat bran were added to the alfalfa solution.

The leachate was prepared by adding $4 \mathrm{~L}$ of tap water to $2.1 \mathrm{~kg}$ of reference diet (wet weight). The mix was then stirred by hand and stored for $24 \mathrm{~h}$ to settle. A syringe was used to siphon off the liquid, which was then filtered using Munktell filter paper, class II, grade 5 and put in a glass bottle with a lid. The leachate was stored in a refrigerator until use.

\section{Climate Chamber}

The climate room at More Research centre, Örnsköldsvik, Sweden were used. The air temperature and humidity were set to $27.6( \pm 0.1){ }^{\circ} \mathrm{C}$ and $63.6( \pm 1.6) \%$. A $12 \mathrm{~h}$ day and $12 \mathrm{~h}$ night light scheme was used. The boxes were placed on a table at one level, ordered so that each treatment was spread horizontally to compensate for potential temperature and humidity gradient (Fig. 2).

\section{Determination of Experimental Parameters}

The following parameters were measured: Total weight of experimental boxes was measured every day (Kern PCB6000-1) and pH was measured the first day (Mettler Toledo MT225 with probe InLab Solids Pro-ISM). The initial dry substance of the PPBS and reference diet was measured based on three replicates of $20 \mathrm{~g}$ each which were dried in $105{ }^{\circ} \mathrm{C}$ for $24 \mathrm{~h}$. All the residual feed in each box were dried for determination of the final dry substance. Air temperature and humidity in the climate chamber were measured using two standard data loggers from Clas Ohlsson, article number 36-4208-1. Final wet and dry weight of the larvae were determined using a Mettler Toledo AG204 DeltaRange. The prepupae were dried at $60{ }^{\circ} \mathrm{C}$ for $48 \mathrm{~h}$. Waste reduction and bio-conversion into larvae biomass were calculated based on dry weights using Eqs. 1 and 2.

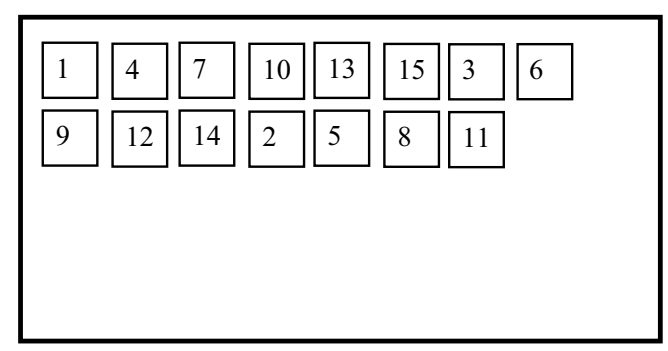

Fig. 2 Placement of boxes in the climate chamber 
Sludge reduction $=\frac{(\text { Initial weight }- \text { residual weight })}{\text { Initial weight }} \times 100 \%$

Bio-conversion $=\frac{\text { Larvae biomass }}{\text { Initial sludge weight }} \times 100 \%$

\section{Statistical Analysis}

The results were statistically analysed with 1 factor ANOVA combined with Tukey HSD/Kramer using the Real Statistics Resource Pack software, Release 5.4 (Charles Zaiontz, www. real-statistics.com).

\section{Results and Discussion}

The dry weight of the prepupae (Fig. 3a) reared on the reference diet (control 1) was $66.5 \mathrm{mg}$, while the prepupae reared on PPBS only (control 2) weigh $0.4 \mathrm{mg}$. Addition of water as a free liquid surface (trial A) resulted in a weight of $0.6 \mathrm{mg}$ and PPBS mixed with leachate combined with water as free liquid surface, $3.5 \mathrm{mg}$ (trial B). Mixing leachate into the PPBS (trial C) resulted in a final weight of $2.0 \mathrm{mg}$ while using leachate as a free liquid surface (trial D) had the highest prepupae weights among those reared on PPBS
(4.8 mg). Only PPBS combined with leachate as free liquid surface (trial D) differ significantly from the other treatments $(\mathrm{p}=0.05)$.

The survival rate of the prepupae (Fig. 3b) reared on reference diet (control 1) was $48.0 \%$ while the survival rate of the prepupae reared on PPBS only (control 2) was $2.0 \%$. Addition of water as a free liquid surface had a survival rate of $1.0 \%$ (trial A) and addition of leachate into the PPBS combined with water as a free liquid surface, $10.3 \%$ (trial B). Mixing leachate into the PPBS (trial C) resulted in a survival rate of $16.0 \%$ while using leachate as a free liquid surface (trial D) had the highest survival rate among those reared on PPBS, $25.7 \%$. Significant differences were: PPBS mixed with leachate (trial C) compared to PPBS only (control 2) and PPBS combined with leachate as free liquid surface (trial D) compared to PPBS mixed with leachate combined with water as free liquid surface (trial B).

The dry weight of the residual diet (Fig. 3c) was lower for the reference diet (control 1), $22.3 \mathrm{~g}$ compared to when PPBS only was used (control 2), $32.7 \mathrm{~g}$. The weight of the residual PPBS when PPBS was combined with water as a free liquid surface, $33.3 \mathrm{~g}$ (trial A) or when leachate was mixed into the PPBS and combined with water as free liquid surface, $32.8 \mathrm{mg}$ (trial B) or leachate mixed into the PPBS, $32.3 \mathrm{~g}$ (trial $\mathrm{C}$ ) or leachate added as a free liquid surface,
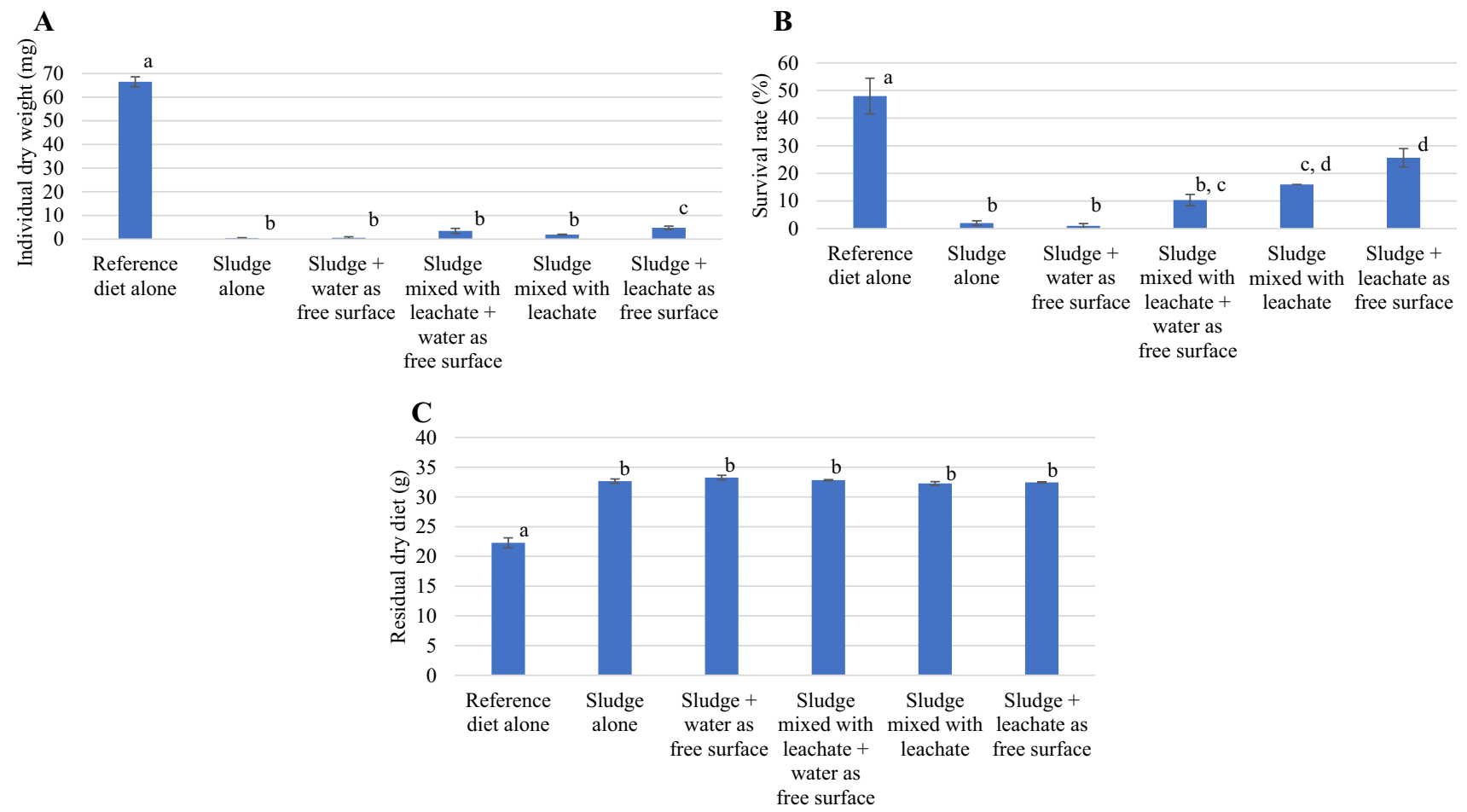

Fig. 3 Prepupae dry weight (a), survival rate (b), dry weight of residual diet (c). The error bars represent the standard deviation. The text under the bars explain the type of substrate used and liquid added. Bars marked with the same lowercase letter do not differ significantly 
$\mathbf{A}$

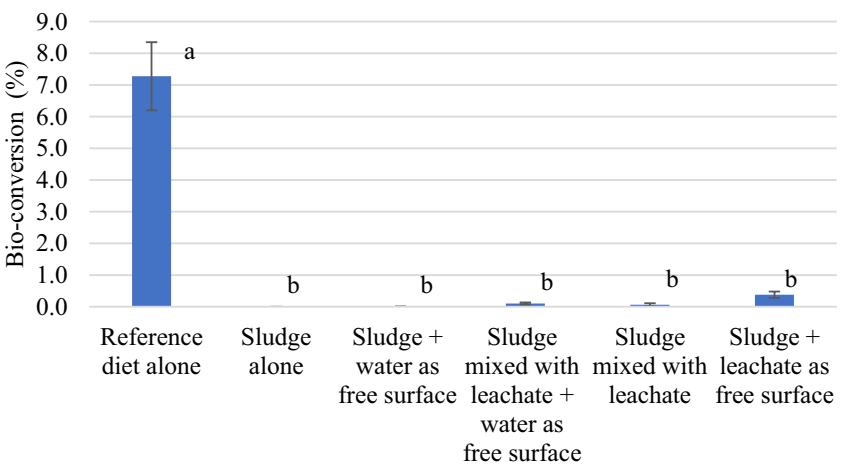

B

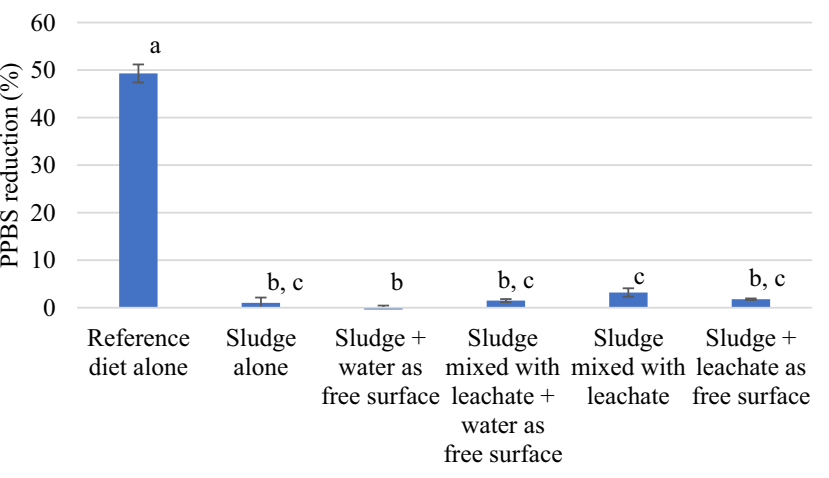

Fig. 4 Bio-conversion rate (a), PPBS reduction (b). The error bars represent the standard deviation. The text under the bars explain the type of substrate used and liquid added. Bars arked with the same letter do not differ significantly

$32.5 \mathrm{~g}$ (trial D) did not differ significantly compared to when PPBS only was used.

The bio-conversion rate of the trial with reference diet is $7.3 \%$ (control 1) (Fig. 4a) while it is $0.0 \%$ for PPBS only (control 2), $0.0 \%$ for PPBS combined with water as free liquid surface (trial A), $0.1 \%$ for PPBS mixed with leachate combined with water as free liquid surface (trial B), $0.1 \%$ for PPBS mixed with leachate (trial C) and $0.4 \%$ for PPBS combined with leachate as free liquid surface (trial D). Only the bio-conversion of the reference diet differs significantly from the other treatments $(\mathrm{p}=0.05)$.

The PPBS reduction of the reference diet is $49.3 \%$ (control 1) (Fig. 4b) while it is $1.1 \%$ for PPBS only (control 2), $0.0 \%$ for PPBS combined with water as free liquid surface (trial A), 1.5\% for PPBS mixed with leachate combined with water as free liquid surface (trial B), 3.2\% for PPBS mixed with leachate (trial C) and $1.8 \%$ for PPBS combined with leachate as free liquid surface (trial D). Significant differences were: the PPBS reduction of the reference diet (control 1) compared to all the other treatments and PPBS combined with leachate as free liquid surface (trial D) compared to PPBS combined with water as free liquid surface (trial A) $(\mathrm{p}=0.05)$.

The final dry weight of the larvae receiving the PPBS was very low compared to the larvae receiving the reference diet (Fig. 3a). However, the difference in final weight is not proportional to the difference in content of nutrients of the PPBS and reference diet (Table 2), which indicates that the nutrients in PPBS are not readily available to the larvae. Lignocellulosic feed media is known to be difficult for the BSFL to utilize because of the content of crude fiber [9] where the larvae need to penetrate through the outer cuticle layer of plant products [10]. The PPBS is of plant origin and contain fibres, therefore it is possible that low availability of the PPBS nutrients contributes to the low prepupae weight.
The lack of substantial weight gain both when leachate was mixed into the sludge and administered as free liquid surface indicates that other factors than low nutrient availability such as pathogens and toxins may also be growth inhibiting to the larvae.

The fact that larvae survival rates increased significantly when leachate was added to the PPBS directly and even more when added as free liquid surface opens up possibilities for further research on how to optimize conditions for possible co-digestion of the PPBS substrate.

The inhibitive impact on larvae dry weight and survival rate could be explained if either harmful bacteria, viruses and toxins like pesticides and heavy metals or a combination of these are present in the PPBS [8]. Juvenile hormones is another a group of substances that have been proven to both impede and improve feeding of some insects [11] and found in i.e. North American native balsam fir [12].

The dry weight and survival rate for the prepupae that received PPBS was much lower than earlier published data for BSFL receiving chicken feed, chicken manure and four types food processing by-products $22.6-48.0 \mathrm{mg}[9,13,14]$ and $72-86 \%[9,14]$ respectively.

The low PPBS reduction (3.2\%) and bio-conversion $(0.4 \%)$ compared to the reference diet (49.3 and $7.3 \%$ respectively) is consistent with the results for the final larvae weight and survival rate.

\section{Conclusion}

The nutrients in PPBS are not readily available to the larvae. Simple manipulations such as adding extra nutrients (leachate) mixed into the PPBS or as free liquid surface did not significantly increase larvae weight gain or bioconversion rate but had a significant effect on larvae survival rates. This 
opens up for possibilities of co-digestion of the substrate by BSFL if effects of inhibiting factors can be minimized.

\section{Further Work}

Future studies should focus on nutritional availability, codigestion and inhibitors e.g. pathogens and toxins. Methods to pre-treat the PPBS to improve the nutritional availability and co-digestion of PPBS and feed additives should be investigated. It is also important to assess the effects of inhibitors in the PPBS and develop methods to handle these substances and organisms.

Acknowledgements Open access funding provided by Mid Sweden University. We are indebted to the pulp and paper mills for assistance with the sampling of the PPBS and to Alnöl AB for help with milling the maize.

Author Contributions All authors contributed to the study conception, design and analysis. Material preparation and data collection were performed by RN. The first draft of the manuscript was written by RN and all authors commented on previous versions of the manuscript. All authors read and approved the final manuscript.

Funding This research was funded by the Swedish Knowledge Foundation (Grant No. 20160260) and Ragn-Sells AB.

\section{Compliance with Ethical Standards}

Conflict of interest Corresponding author Robert Norgren is employed by Ragn-Sells AB.

Open Access This article is distributed under the terms of the Creative Commons Attribution 4.0 International License (http://creativeco mmons.org/licenses/by/4.0/), which permits unrestricted use, distribution, and reproduction in any medium, provided you give appropriate credit to the original author(s) and the source, provide a link to the Creative Commons license, and indicate if changes were made.

\section{References}

1. Sivard, Å., Ericsson, T., Krogerus, M., Stemme, S.: Nuvärdesmaterial kring bioslam [Current situation for biosludge]. ÅF Industry AB, Stockholm (2013)

2. Norgren, R., Morgan, F., Björkqvist, O.: Pulp mill bio-sludgesludge properties and recycling. In: DIVA (2016)

3. Norgren, R., Fröling, M., Björkqvist, O.: Industrial symbiosis solutions for recycling of biosludge from the pulp industry. In: DiVA-Academic Archive On-line (2015)
4. Mahmood, T., Elliott, A.: A review of secondary sludge reduction technologies for the pulp and paper industry. Water Res. 40, 2093-2112 (2006). https://doi.org/10.1016/j.watres.2006.04.001

5. Booram, C.V., Newton, G.L., Barker, R.W., Hale, O.M.: Value of Hermetia illucens as an alternate protein source. In: Paper American Society of Agricultural Engineers. p. 12. American Society of Agricultural and Biological Engineers, St. Joseph, MI, USA (1975)

6. Cai, M., Hu, R., Zhang, K., Ma, S., Zheng, L., Yu, Z., Zhang, J.: Resistance of black soldier fly (Diptera: Stratiomyidae) larvae to combined heavy metals and potential application in municipal sewage sludge treatment. Environ. Sci. Pollut. Res. 25, 1559-1567 (2018). https://doi.org/10.1007/s11356-017-0541-x

7. Cheng, J.Y.K., Chiu, S.L.H., Lo, I.M.C.: Effects of moisture content of food waste on residue separation, larval growth and larval survival in black soldier fly bioconversion. Waste Manag. 67, 315-323 (2017). https://doi.org/10.1016/j.wasman.2017.05.046

8. Huis, A., Tomberlin, J.K. (eds.): Insects as food and feed: from production to consumption. Wageningen Academic Publishers, The Netherlands (2017)

9. Rehman, K. ur, Cai, M., Xiao, X., Zheng, L., Wang, H., Soomro, A.A., Zhou, Y., Li, W., Yu, Z., Zhang, J.: Cellulose decomposition and larval biomass production from the co-digestion of dairy manure and chicken manure by mini-livestock (Hermetia illucens L,). J. Environ. Manage. 196, 458-465 (2017). https:// doi.org/10.1016/j.jenvman.2017.03.047

10. Mohd-Noor, S.-N., Wong, C.-Y., Lim, J.-W., Mah-Hussin, M.-I.A., Uemura, Y., Lam, M.-K., Ramli, A., Bashir, M.J.K., Tham, L.: Optimization of self-fermented period of waste coconut endosperm destined to feed black soldier fly larvae in enhancing the lipid and protein yields. Renew. Energy. 111, 646-654 (2017). https://doi.org/10.1016/j.renene.2017.04.067

11. Jiang, Z., Shang, Z., Zhao, S., Chiu, S.: The relationship between insect growth regulators with juvenile hormone activity and insect feeding behavioural response. Insect Sci 6, 71-76 (1999). https:// doi.org/10.1111/j.1744-7917.1999.tb00012.x

12. Kawai, K., Takahashi, C., Numata, A., Chernysh, S., Nesin, A., Numata, H.: Juvenile hormone activity of juvabione analogues against Pyrrhocoris apterus (Hemiptera: Pyrrhocoridae). Appl. Entomol. Zool. 28, 118-121 (1993). https://doi.org/10.1303/ aez.28.118

13. Diener, S., Zurbrügg, C., Tockner, K.: Conversion of organic material by black soldier fly larvae: establishing optimal feeding rates. Waste Manag. Res. 27, 603-610 (2009). https://doi. org/10.1177/0734242X09103838

14. Oonincx, D.G.A.B., van Broekhoven, S., van Huis, A., van Loon, J.J.A.: Feed conversion, survival and development, and composition of four insect species on diets composed of food by-products. PLoS ONE 10, e0144601 (2015). https://doi.org/10.1371/journ al.pone.0144601

Publisher's Note Springer Nature remains neutral with regard to jurisdictional claims in published maps and institutional affiliations. 


\section{Affiliations}

\section{R. Norgren ${ }^{1,2}\left(\mathbb{0} \cdot\right.$ O. Björkqvist ${ }^{3} \cdot$ A. Jonsson ${ }^{4}$}

O. Björkqvist

3 Mid Sweden University, 85170 Sundsvall, Sweden olof.bjorkqvist@miun.se

A. Jonsson

4 Mid Sweden University, Kunskapens väg 8, anders.jonsson@miun.se 83125 Östersund, Sweden

1 Mid Sweden University, 85170 Sundsvall, Sweden

2 Ragn-Sells AB, 86136 Timrå, Sweden 